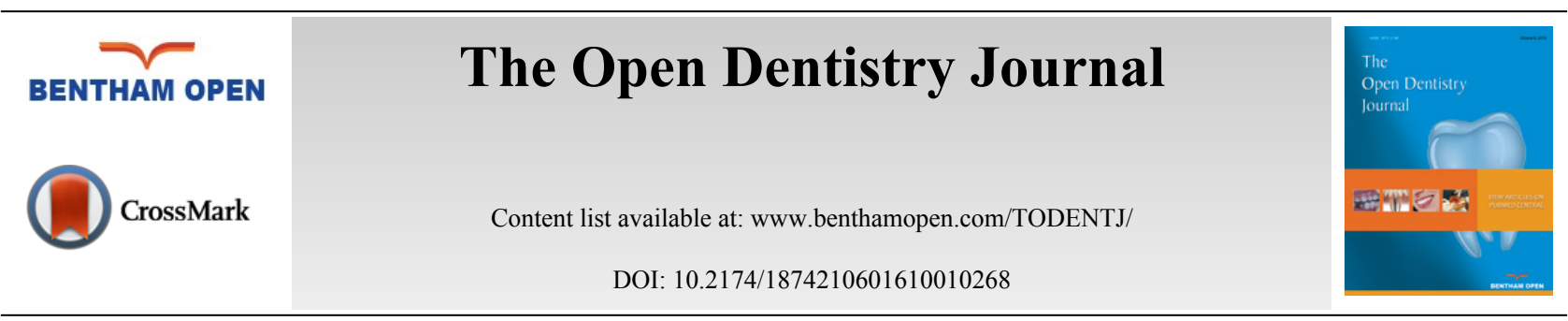

\title{
Bond Strength of a Novel One Bottle Multi-mode Adhesive to Human Dentin After Six Months of Storage
}

\author{
Fernanda Borguetti Manfroi ${ }^{1}$, Maurem Leitão Marcondes ${ }^{1}$, Deise Caren Somacal ${ }^{1}$, Gilberto Antonio \\ Borges $^{2}$, Luiz Henrique Burnett Júnior ${ }^{1}$ and Ana Maria Spohr ${ }^{3, *}$ \\ ${ }^{I}$ Department of Restorative Dentistry, School of Dentistry, Pontifical Catholic University of Rio Grande do Sul, Porto \\ Alegre, Brazil \\ ${ }^{2}$ Department of Restorative Dentistry, Uberaba University, Uberaba, Brazil \\ ${ }^{3}$ Department of Dental Materials, School of Dentistry, Pontifical Catholic University of Rio Grande do Sul, Porto \\ Alegre, Brazil
}

\section{Abstract:}

\section{Objective:}

The aim of the study was to evaluate the microtensile bond strength ( $\mu$ TBS) of Scotchbond Universal to dentin using the etch-andrinse or the self-etch technique after $24 \mathrm{~h}$ and 6 months of storage.

\section{Materials and Methods:}

Flat dentin surfaces were obtained in 24 third molars. The teeth were divided into four groups: G1 - Scotchbond Universal applied in the etch-and-rinse mode; G2 - Scotchbond Universal applied in the self-etch mode; G3 - Scotchbond Multi-Purpose; G4 - Clearfil SE Bond. A block of composite was built on the adhesive area. The tooth/resin sets were cut parallel to the long axis to obtain 40 beams $\left(\sim 0.8 \mathrm{~mm}^{2}\right)$ for each group. Twenty specimens were immediately submitted to the $\mu$ TBS test, and the remaining 20 were stored in water for 6 months. Failures and the adhesive interface were analyzed by SEM.

\section{Results:}

According to two-way ANOVA, the interaction between adhesive and storage time was significant $(p=0.015)$.The $\mu$ TBS (MPa)

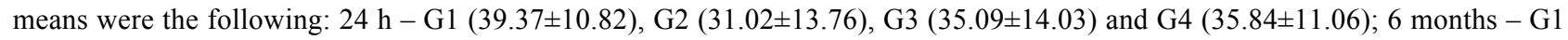

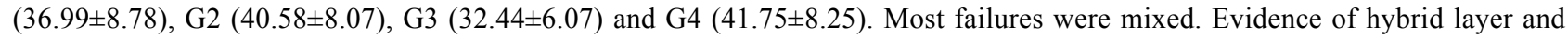
numerous resin tags were noted for Scotchbond Universal applied with the etch-and-rinse mode and Scotchbond Multi-Purpose. A thinner hybrid layer and fewer resin tags were noted for Scotchbond Universal applied in the self-etch mode and Clearfil SE Bond.

\section{Conclusion:}

The results indicate that the $\mu$ TBS for Scotchbond Universal is comparable to the gold-standard adhesives. Scotchbond Universal applied in the self-etch mode and Clearfil SE Bond revealed higher bond stability compared to the etch-and-rinse mode.

Keywords: Adhesive systems, Bond strength, Dentin, Interface, Microtensile, Storage.

\section{INTRODUCTION}

Adhesive systems have been largely used in dentistry. Materials can be classified in either an etch-and-rinse system or a self-etch adhesive system [1]. The former utilizes three components (acid, primer and bond separately) or two

\footnotetext{
* Address correspondence to this author at the School of Dentistry - Pontifical Catholic University of Rio Grande do Sul, Avenida Ipiranga, 6681 90616-900 Porto Alegre, RS, Brazil; Tel/Fax: +55-51-33203538; E-mail: ana.spohr@pucrs.br
} 
components (acid separately, and primer and bond in the same bottle). The latter utilizes two components (self-etch primer and bond separately) or one component (self-etch primer and bond in the same bottle).

One of the challenges in dentistry is bonding restorative materials to such different substrates as enamel and dentin [2]. Traditionally, the bond to enamel is regarded as safe and trustworthy, but the bond to dentin has been unreliable and less predictable [3]. Bonding to dentin is more complex than bonding to enamel because of the histologic differences between the two substrates [4].

In the etch-and-rinse adhesive system, the phosphoric acid is first applied to remove the smear layer and demineralize the dentin surface to expose the inorganic portion. Subsequently, the primer is applied followed by the bond, which infiltrates the exposed collagen in the demineralized dentin and creates a hybrid layer or interdiffusion zone [5]. In the self-etch adhesive system, the etching is made by acidic resin monomers, which simultaneously demineralize and infiltrate the dentin [6]. Depending on which acidic monomer is used, the self-etch adhesive systems can cause partial and superficial demineralization of the smear layer and dentin because of the presence of weaker acid, which is different from the etch-and-rinse adhesive systems [7, 8]. Within these categories, the Scotchbond MultiPurpose adhesive system (3M/ESPE) is considered the gold standard for the etch-and-rinse adhesive systems. Clearfil SE Bond (Kuraray) is considered the gold standard for the self-etch adhesive systems; this is because both adhesive systems have demonstrated the best results of bond strength to dentin [9].

Parallel to the study of bond strength, the scanning electron microcopy (SEM) has been used to evaluate the interfaces between different restorative materials and the dental substrates [10,11]. In the case of adhesive systems applied to dentin, the SEM allows to analyze the morphology of the hybrid layer obtained with different adhesive systems, as well as the resin tags [12]. SEM images show that the etch-and-rinse adhesive systems have thicker hybrid layers and longer resin tags compared with self-etch adhesive systems [13].

Recently, a new one-bottle adhesive system called Scotchbond Universal was launched in the market. According to the manufacturer, this adhesive system is classified as "multi-mode" or "universal" because it can be applied using either the etch-and-rinse or the self-etch technique as well as on different materials. Regardless of the commercial presentation and the technique application, it is important to know if Scotchbond Universal is comparable or has a better performance compared to gold standards adhesive systems.

The aim of the current study was to evaluate the microtensile bond strength ( $\mu$ TBS) of Scotchbond Universal to dentin, using the etch-and-rinse or the self-etch technique after $24 \mathrm{~h}$ and six months of storage. This study was conducted under the null hypothesis that no significant difference in bond strength exists between Scotchbond Universal and respective gold standard of each adhesive technique tested.

\section{MATERIALS AND METHODS}

\section{Tooth Preparation}

Thirty-two unerupted human third molars, extracted for therapeutic reasons, were obtained from the Tooth Bank after approval was given by the Ethics Committee of the Pontifical Catholic University of Rio Grande do Sul (PUCRS), protocol number 11633412.5.0000.5336.

The teeth were cleaned of gross debris and stored in distilled water at $4{ }^{\circ} \mathrm{C}$. The water was changed every week, and the teeth were used within 6 months. The roots were mounted in self-cured acrylic resin, and the occlusal enamel surface was removed using a diamond disc mounted in a low-speed laboratory cutting machine (Labcut 1010, Extec Corp., London, UK) under cooling. The remainder of the enamel was removed using 400-grit silicon carbide abrasive paper in a polishing machine (DPU-10, Panambra, São Paulo, SP, Brazil) under water. The superficial dentin was exposed and finished with 600-grit silicon carbide abrasive paper in the polishing machine, and a flat dentin surface was obtained.

\section{Bonding Procedures}

The teeth were randomly divided into four groups, which differ in the materials used (Table 1). 
Table 1. Adhesive systems used in the study.

\begin{tabular}{|c|c|c|c|c|}
\hline Material & Description & Batch & Composition & Manufacturer \\
\hline $\begin{array}{c}\text { Scotchbond } \\
\text { universal }\end{array}$ & Adhesive system & 475261 & $\begin{array}{c}\text { Organophosphate monomer (MDP), } \\
\text { dimethacrylate resins (BisGMA, etc), HEMA, vitrebond } \\
\text { copolymer, filler, ethanol, water, initiators, silane }\end{array}$ & $\begin{array}{c}\text { 3M/ESPE, St. Paul, MN, } \\
\text { USA }\end{array}$ \\
\hline $\begin{array}{c}\text { Scotchbond } \\
\text { multi-purpose }\end{array}$ & Adhesive system & $\begin{array}{c}\text { N271103 } \\
\text { Adhesive: } \\
\text { N296740 }\end{array}$ & $\begin{array}{c}\text { Primer: Aqueous solution of HEMA, polyalkenoic acid. } \\
\text { Adhesive: Bis-GMA, HEMA, photoinitiator system }\end{array}$ \\
\hline 3M/ESPE, St. Paul, MN, \\
USA
\end{tabular}

Group 1 - Scotchbond Universal applied in the etch-and-rinse mode: the dentin was etched with $35 \%$ phosphoric acid for $15 \mathrm{~s}$, followed by rinsing with air and a water spray for $15 \mathrm{~s}$. The excess water was removed with cotton buds. The adhesive was applied with a microbrush and scrubbed for $20 \mathrm{~s}$, followed by gentle air-drying for $5 \mathrm{~s}$. The adhesive was light cured for $10 \mathrm{~s}$ with a light-curing unit (Optilux Plus, Gnatus, Ribeirão Preto, SP, Brazil). The light intensity was controlled by a radiometer (Model 100 Demetron, Kerr, Danbury, CT) between 450 and $500 \mathrm{~mW} / \mathrm{cm}^{2}$.

Group 2 - Scotchbond Universal applied in the self-etch mode: the adhesive was applied to the dentin with a microbrush and scrubbed for $20 \mathrm{~s}$, followed by gentle air drying for $5 \mathrm{~s}$ and light-curing for $10 \mathrm{~s}$.

Group 3 - Scotchbond Multi-Purpose: the dentin was etched with 35\% phosphoric acid for $15 \mathrm{~s}$, followed by rinsing with air and a water spray for $15 \mathrm{~s}$. The excess water was removed with cotton buds. A layer of primer was applied, followed by gentle air-drying for $5 \mathrm{~s}$. Subsequently, the bond was applied with a microbrush and light cured for $10 \mathrm{~s}$.

Group 4 - Clearfil SE Bond: the self-etching primer was applied to the dentin using a microbrush and was left in place for $30 \mathrm{~s}$. Excess solvent was removed by air drying for $5 \mathrm{~s}$. The bond was applied using a microbrush, followed by gentle air drying for $3 \mathrm{~s}$ and light-curing for $20 \mathrm{~s}$.

After the adhesive systems were applied, the surface was built up using three layers of Z250 (3M, St. Paul, MN, USA) composite resin to result in a height of $6 \mathrm{~mm}$. Each layer was light cured for $40 \mathrm{~s}$. The specimens were stored for $24 \mathrm{~h}$ at $37^{\circ} \mathrm{C}$ in distilled water.

\section{Microtensile Testing}

Six tooth/resin composite sets per group were sectioned perpendicular to the bonding surface using a laboratorycutting machine (Labcut 1010) at $400 \mathrm{rpm}$ with a diamond disk under water-cooling. The specimens were cut into approximately $0.90 \times 0.90 \mathrm{~mm}$ transverse sections, measured with a digital caliper (Mitutoyo Sul Americana Ltda., Suzano, SP, Brazil). Eight beams from the central region of each tooth were obtained and were examined with a stereomicroscope (Olympus Corp., Tokyo, Japan) at $25 \times$ magnification to analyze the adhesive area. The specimens presenting defects, such as bubbles, lack of material or irregular areas, were discarded. Twenty beams were immediately submitted to microtensile bond strength test, and the other twenty beams were tested after six months of storage in distilled water at $37^{\circ} \mathrm{C}$.

The specimens were fitted to the microtensile-testing device for analyzing. This device had two stainless steel grips, which had a surface area of $8 \times 10 \mathrm{~mm}$ and sliding shafts that prevent torsion movements during the tests. These shafts had a fixation screw that prevented the specimen from moving during bonding. The specimens were fixed with cyanoacrylate glue (Loctite, São Paulo, SP, Brazil), associated with the Zip Kicker accelerator (Pacer Technology, Rancho Cucamonga, CA, USA), and stressed at a crosshead speed of $0.5 \mathrm{~mm} / \mathrm{min}$ until failure in a universal testing machine (EMIC DL-2000, São José dos Pinhais, PR, Brazil) using a cell load of 50 N. The $\mu$ TBS was expressed in MPa and derived by dividing the imposed force $(\mathrm{N})$ at the time of fracture by the bond area $\left(\mathrm{mm}^{2}\right)$.

The fractured surfaces of all specimens were observed by using scanning electron microscopy (SEM) (EVO LS15, Zeiss - Germany). The failures were classified as adhesive (failure between adhesive and dentin), cohesive in adhesive (failure inside the adhesive), interfacial (adhesive and cohesive in adhesive), cohesive in dentin (failure inside the dentin), cohesive in composite resin (failure in composite resin), or mixed (two or more types of failure). 


\section{Statistical Analysis}

$\mu$ TBS values were analyzed using a two-way ANOVA (adhesive system x storage time) and post-hoc multiple comparisons using Tukey's test. $P \leq 0.05$ was considered significant. The software used was SPSS v10.0 (SPSS Inc., Chicago, IL, USA).

\section{Bond Interface Analysis}

Two beams from each group were included in epoxy resin. The bond interfaces were polished with 400-, 600-, 1000- and 1200-grit silicone carbide abrasive papers and wetted with water using manual pressure and rotary movements. The interfaces were then polished with 6-, 3-, 1- and 0.25- $\mu \mathrm{m}$ grit diamond pastes on a felt disk with manual pressure. All of the specimens were ultrasonically cleaned in distilled water for 10 min to remove the polishing residues. The specimens were then immersed in a hydrochloric acid solution $(6 \mathrm{M} \mathrm{HCl})$ for 2 min and then washed with distilled water. Shortly thereafter, the samples were deproteinized in a $1 \%$ sodium hypochlorite solution $(\mathrm{NaOCl})$ for 10 min and washed in distilled water. The specimens were dried at room temperature for 7 days. The beams were mounted in stubs, gold-sputter coated (Bal-Tec, Balzers, Liechtenstein) and observed using scanning electronic microscope (EVO LS15, Zeiss - Germany). The bond interfaces of all the specimens were observed at $1.500 \times$ magnification. Representative images of each group were recorded and used to qualitatively describe the topography of the dentin/adhesive interface.

\section{RESULTS}

Two-way ANOVA analysis revealed that the adhesive system $(p=0.110)$ and the storage time $(p=0.108)$ had no significant effect on the $\mu$ TBS, while the interaction effect was significant $(p=0.015)$. Table 2 shows the $\mu$ TBS means obtained from the different groups.

Table 2. $\mu$ TBS means (MPa) and standard deviation $( \pm$ SD) for the groups at $24 \mathrm{~h}$ and 6 months of storage.

\begin{tabular}{|c|c|c|}
\hline Group & Mean + SD (MPa) - 24 h & Mean + SD (MPa) - 6 months \\
\hline $\begin{array}{c}\text { Scotchbond universal } \\
\text { (etch-and-rinse mode) }\end{array}$ & $39.37 \mathrm{Aa}( \pm 10.82)$ & $36.99 \mathrm{ABa}( \pm 8.78)$ \\
\hline $\begin{array}{c}\text { Scotchbond universal } \\
\text { (self-etch mode) }\end{array}$ & $31.02 \mathrm{Aa}( \pm 13.76)$ & $40.58 \mathrm{Ab}( \pm 8.07)$ \\
\hline Scotchbond multi-purpose & $35.09 \mathrm{Aa}( \pm 14.03)$ & $32.44 \mathrm{Ba}( \pm 6.07)$ \\
\hline Clearfil SE bond & $35.84 \mathrm{Aa}( \pm 11.06)$ & $41.75 \mathrm{Ab}( \pm 8.25)$ \\
\hline
\end{tabular}

Means followed by the same capital letter in columns and by the same lowercase letter in lines do not present significant differences according Tukey's test $(\alpha=0.05)$.

At the $24 \mathrm{~h}$ of storage time point, no significant differences existed in $\mu$ TBS values among adhesive systems. However, at the 6-month time point, a significant difference was noted among the adhesive systems. Clearfil SE Bond obtained the highest $\mu$ TBS mean $(41.75 \mathrm{MPa})$, which was not significantly different from Scotchbond Universal when applied in either the self-etch mode $(40.58 \mathrm{MPa})$ or the etch-and-rinse mode $(36.99 \mathrm{MPa})$. Scotchbond Universal applied in the etch-and-rinse mode was not significantly different from Scotchbond Multi-Purpose (32.44 MPa).

Clearfil SE Bond and Scotchbond Universal applied in the self-etch mode obtained statistically higher $\mu$ TBS means at 6 months of storage compared to the same adhesive systems at the $24 \mathrm{~h}$ of storage time point. Scotchbond Universal applied in the etch-and-rinse mode and Scotchbond Multi-Purpose had a decrease in $\mu$ TBS means at 6 months of storage but was not significantly different from the $24 \mathrm{~h}$ of storage time point.

Most failures were mixed at $24 \mathrm{~h}$ and at 6 months of storage, except for Scotchbond Multi-Purpose at 6 months of storage, in which the failures were predominantly interfacial (Fig. 1(1)) at 6 months of storage. The mixed failures were divided into two types: a) interfacial and cohesive in composite resin (Fig. 1(2)) and b) cohesive in adhesive and cohesive in composite resin (Fig. 1(3)). In total, at least 75\% or more were mixed failures for Scotchbond Universal when applied in the etch-and-rinse and self-etch modes and for Clearfil SE Bond. Scotchbond Multi-Purpose resulted in $45 \%$ of samples having an interfacial failure at $24 \mathrm{~h}$ of storage and $60 \%$ at 6 months of storage. There were no failures in the adhesive alone, cohesive in adhesive, cohesive in dentin or cohesive in composite resin (Table 3 ). 
Table 3. Failure mode analysis.

\begin{tabular}{|c|c|c|c|c|c|c|c|c|}
\hline \multirow{2}{*}{$\begin{array}{c}\text { Adhesive System } \\
\text { Failure Mode/ Storage Time } \\
\text { (1) Interfacial }\end{array}$} & \multicolumn{2}{|c|}{$\begin{array}{l}\text { Scotchbond Universal (etch- } \\
\text { and-rinse mode) } 24 \mathrm{~h} 6 \\
\text { months }\end{array}$} & \multicolumn{2}{|c|}{$\begin{array}{c}\text { Scotchbond Universal } \\
\text { (self-etch mode) } 24 \text { h } 6 \\
\text { months }\end{array}$} & \multicolumn{2}{|c|}{$\begin{array}{l}\text { Scotchbond Multi-Purpose } \\
24 \text { h } 6 \text { months }\end{array}$} & \multicolumn{2}{|c|}{$\begin{array}{l}\text { Clearfil SE Bond } \\
24 \mathrm{~h} \quad 6 \text { months }\end{array}$} \\
\hline & $20 \%$ & $25 \%$ & $20 \%$ & $15 \%$ & $45 \%$ & $60 \%$ & $20 \%$ & $20 \%$ \\
\hline $\begin{array}{l}\text { (2) Mixed (interfacial }+ \text { cohesive } \\
\text { in composite resin) }\end{array}$ & $45 \%$ & $45 \%$ & $50 \%$ & $50 \%$ & $30 \%$ & $25 \%$ & $40 \%$ & $35 \%$ \\
\hline $\begin{array}{l}\text { (3) Mixed (cohesive in adhesive }+ \\
\text { cohesive in composite resin) }\end{array}$ & $35 \%$ & $30 \%$ & $30 \%$ & $35 \%$ & $25 \%$ & $15 \%$ & $40 \%$ & $45 \%$ \\
\hline
\end{tabular}

When examining the bond interface using SEM, evidence of hybrid layer formation and numerous resin tags were noted for Scotchbond Universal applied with the etch-and-rinse mode (Fig. 2) and Scotchbond Multi-Purpose (Fig. 3). A thinner hybrid layer and fewer resin tags were noted for Scotchbond Universal applied in the self-etch mode (Fig. 4) and Clearfil SE Bond (Fig. 5).
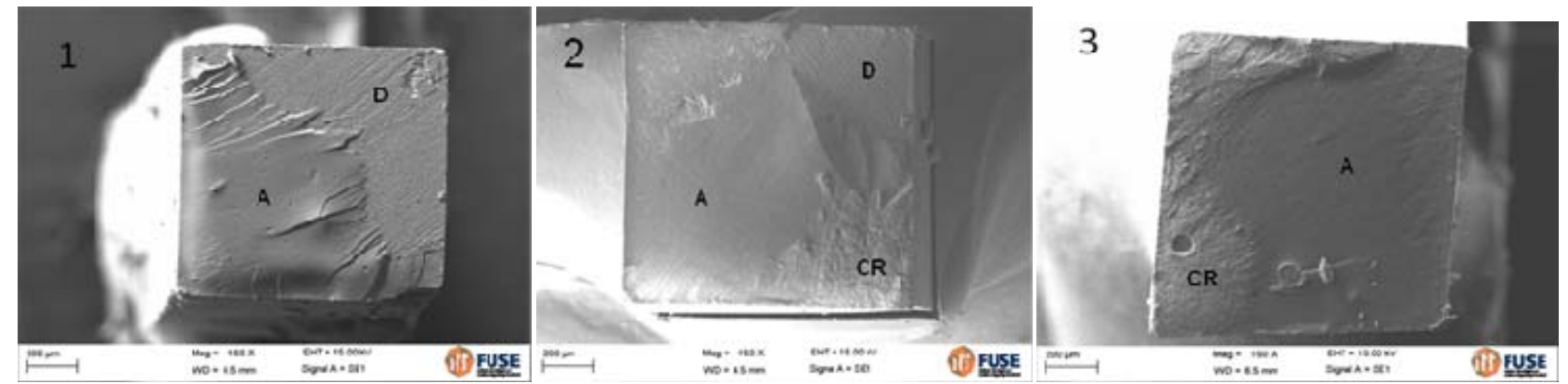

Fig. (1). SEM images of different failure modes.

(1) -Scotchbond multi-purpose. Interfacial failure: A - adhesive; D - dentin.

(2) -Scotchbond universal applied in the etch-and-rinse mode. Mixed failure (interfacial + cohesive in composite resin): CR composite resin; D - dentin; A - adhesive.

(3) -Scotchbond universal applied in the etch-and-rinse mode. Mixed failure (cohesive in adhesive + cohesive in composite resin): A - adhesive; CR - composite resin.

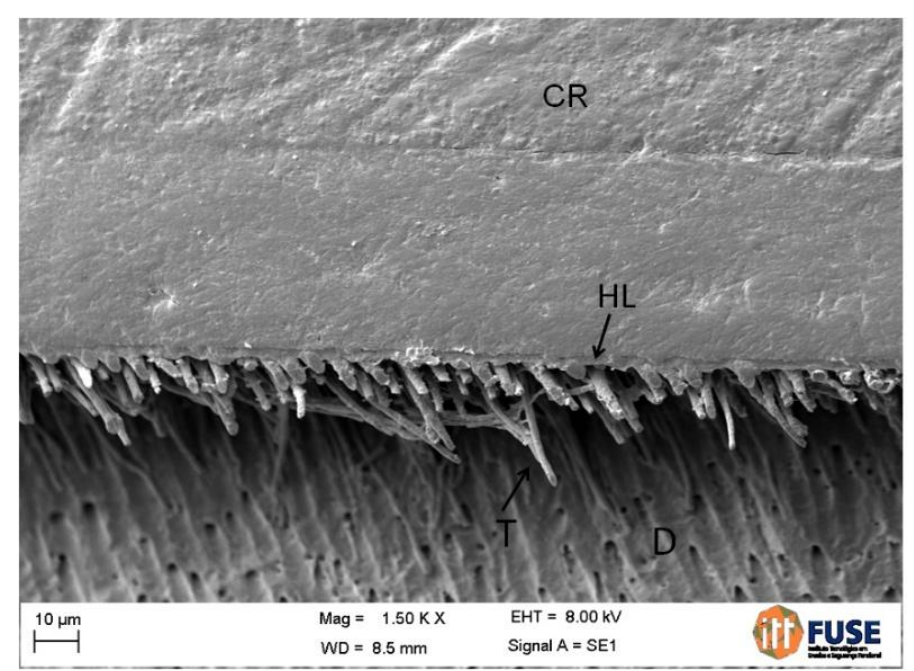

Fig. (2). SEM image of the interface of scotchbond universal applied in the etch-and- rinse mode: CR - composite resin; HL - hybrid layer; $\mathrm{T}$ - tags; $\mathrm{D}$ - dentin. 


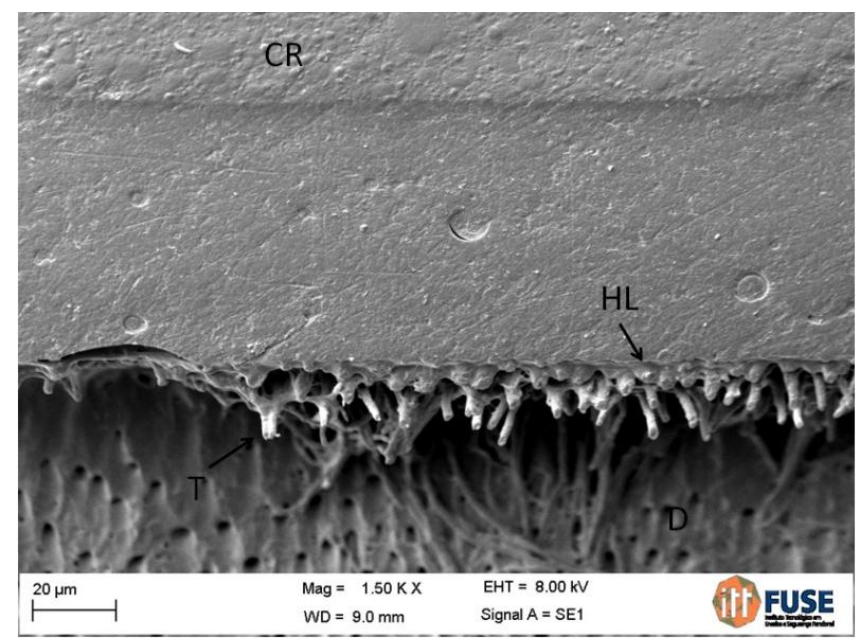

Fig. (3). SEM image of scotchbond multi-purpose: $C R$ - composite resin; HL - hybrid layer; $\mathrm{T}$ - tags; D - dentin.

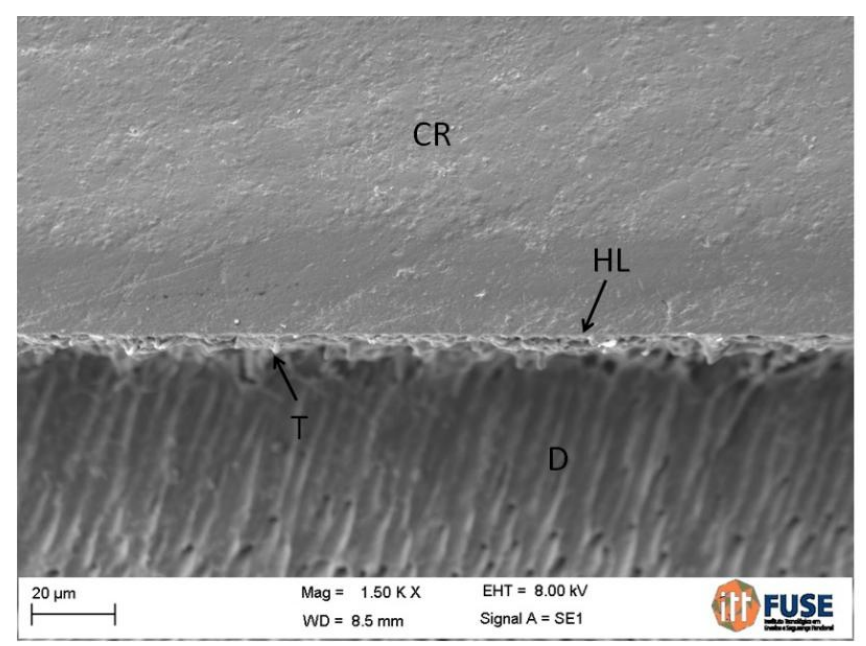

Fig. (4). SEM image of scotchbond universal applied in the self-etch mode: CR - composite resin; HL - hybrid layer; T - tags; D dentin.

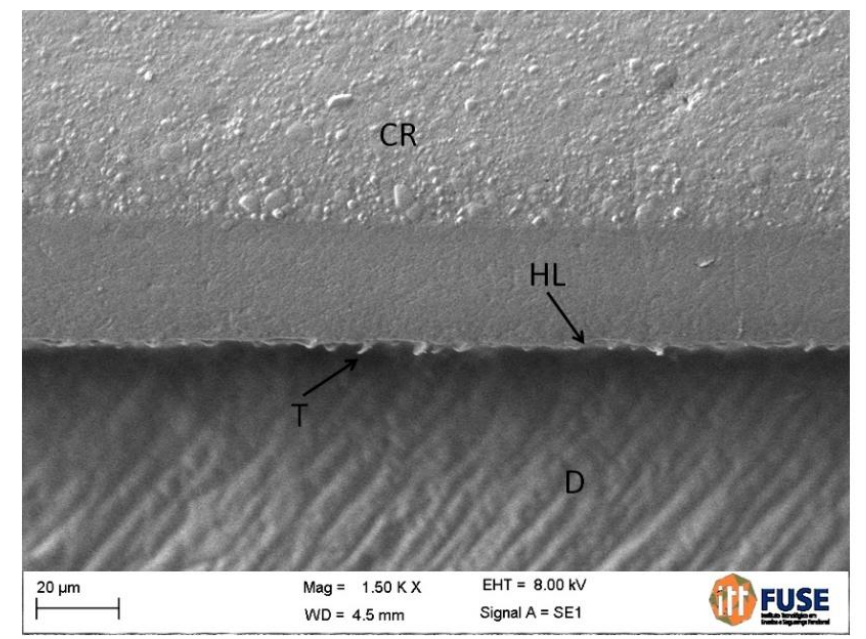

Fig. (5). SEM image of clearfil SE bond: CR - composite resin; HL - hybrid layer; $\mathrm{T}$ - tags; D - dentin.

\section{DISCUSSION}

The null hypothesis was accepted because the $\mu$ TBS values of Scotchbond Universal applied in the etch-and-rinse 
and self-etch modes were not significantly different from Scotchbond Multi-Purpose and Clearfil SE Bond when adhering to dentin.

The Scotchbond Universal adhesive system includes the 10-methacryloyloxydecyl dihydrogen phosphate monomer (10-MDP) in its composition, which provides acidity to the adhesive and, consequently, the capability to etch the dentin surface. Although the presence of this acidic monomer allows for the self-etch ability of the adhesive, the manufacturer claims that the Scotchbond Universal can be applied on dentin after the $35 \%$ phosphoric acid etching. Therefore, the application of this adhesive system in the etch-and-rinse or self-etch mode depends on the professional's choice.

At both the $24 \mathrm{~h}$ and 6 months of storage evaluation time points, no significant difference was found in the $\mu$ TBS between the etch-and-rinse and self-etch mode for Scotchbond Universal. Currently, a preference exists for the self-etch adhesive system on dentin because of the less deep demineralization compared to $35 \%$ phosphoric acid [14]. In addition to that, the water-removing step after etching with phosphoric acid is eliminated; this step is considered one of the most critical steps during the etch-and-rinse adhesive system application [15].

Several morphological differences can be observed in the bond interfaces between etch-and-rinse and self-etch techniques for Scotchbond Universal. In the etch-and-rinse adhesive system, the etching of the dentin with $35 \%$ phosphoric acid for $15 \mathrm{~s}$ causes the removal of the smear layer and smear plugs, the opening of the dentin tubules and demineralization of intertubular and peritubular dentin to a depth of approximately $5 \mu \mathrm{m}$ [8]. Subsequently, the adhesive included in the one bottle is applied and light-cured. In the self-etch adhesive system, as the acidic monomer demineralizes, the other components of the adhesive infiltrate the demineralized dentin [1]. The demineralization depth depends on the $\mathrm{pH}$ of the acid monomer. The adhesive systems containing 10-MDP have a $\mathrm{pH}$ of approximately 2 , which is considered a mild adhesive system. These adhesive systems cause partial demineralization of the dentin and formation of a hybrid layer with a thickness of $1 \mu \mathrm{m}$ or less [8, 16].Thus, SEM confirmed the formation of a thicker hybrid layer and numerous long resin tags for both Scotchbond Universal applied in the etch-and-rinse mode and Scotchbond Multi-Purpose compared to both Scotchbond Universal applied in the self-etch mode and Clearfil SE Bond. Using TEM, Yoshida et al. [17] found a hybrid layer with 0,2-0,5 $\mu \mathrm{m}$ thickness for Scotchbond Universal and 0,5-0,7 $\mu \mathrm{m}$ thickness for Clearfil SE Bond. Although morphological differences are apparent in the bond interface between the etch-and-rinse and self-etch adhesive systems, these differences were not significantly reflected in the $\mu$ TBS values, which corroborates with other studies $[14,18]$.

After 6 months of storage in distilled water, a slight decrease in $\mu$ TBS was noted for Scotchbond Universal applied in the etch-and-rinse mode when compared to the $24 \mathrm{~h}$ evaluation, but no significant difference was noted. A similar result was observed for Scotchbond Multi-Purpose. However, for Scotchbond Universal applied in the self-etch mode, a significant increase in the $\mu$ TBS was found after 6 months of storage. One of the possible explanations for the difference in $\mu$ TBS observed between etch-and-rinse and self-etch modes can be related to the incomplete infiltration of the resin monomers in the deeper layers of the dentin demineralized by phosphoric acid [19]; this would leave the collagen fibrils exposed to the hydrolytic degradation [20]. Marchesi et al. [21] demonstrated that Scotchbond Universal applied in the self-etch mode showed lower silver uptake when compared to the same adhesive applied with the etchand-rinse mode.

Scotchbond Universal applied in the self-etch mode and Clearfil SE Bond presented higher $\mu$ TBS after 6 months of storage. This finding is interesting because it occurred for the two adhesive systems that had similarities between their compositions. Both adhesive systems contain 10-MDP. This monomer has the ability to bond chemically to the hydroxyapatite present in dentin and enamel [22]. In the self-etch mode, the residual hydroxyapatite that remains around the collagen fibrils interacts with the 10-MDP monomer improving the bond [22, 23]. Yoshida et al. [22] demonstrated that chemical bonds promoted by 10-MDP are not only more effective but are also more stable in water compared to other functional monomers, such as 4-methacryloxyethyl trimellitic acid (4-MET) and Phenyl-P. In addition, the bond of 10-MDP to calcium creates a salt (MDP-Ca) that protects against hydrolysis [24] because it is a hydrolytically stable salt [25]. Therefore, the presence of 10-MDP and the formation of a hybrid layer containing less collagen fibrils that were exposed to degradation may have contributed to a more stable interface [17].

Even though Scotchbond Universal contains less 10-MDP in its composition compared to Clearfil SE Bond [17], this adhesive contains polyalkenoic acid copolymer, which provides chemical bonding through its spontaneous bonding to hydroxyapatite [26]. More than $50 \%$ of the carboxyl groups in the polyalkenoic acid copolymer are capable of bonding to hydroxyapatite. Carboxylic groups replace phosphate ions on the substrate and create ionic bonds with calcium [27]. Most likely, the presence of polyalkenoic acid copolymer has led to higher bond stability between dentin 
and adhesive during the 6 months of storage.

Scotchbond Multi-Purpose obtained lower $\mu$ TBS in comparison with Clearfil SE Bond and Scotchbond Universal in the self-etch mode after 6 months of storage in water. Two main possible explanations can be given for this difference in $\mu$ TBS between the adhesive systems: a) incomplete infiltration of the resin monomers in the deeper layers of the dentin demineralized by phosphoric acid [19], leaving the collagen fibrils exposed to the hydrolytic degradation [20]; b) Scotchbond Multi-Purpose does not have 10-MDP monomer, which protect against hydrolysis [24] due to the ability to bond chemically to the hydroxyapatite present in dentin and enamel [22].

Scotchbond Universal is a one-bottle simplified adhesive system. Other adhesive systems in the same category have shown higher hydrolytic degradation compared with three-step adhesive systems or two-step self-etch adhesives that have a self-primer and a bonding agent. This higher degradation occurs because simplified adhesives contain higher quantities of hydrophilic monomers in their composition compared to three-step systems [28], and they also lack a hydrophobic layer [29]. The lack of a hydrophobic bonding layer in the one-step self-etch adhesive formulations have been demonstrated to reduce bond stability over time because the bonded interfaces behave as semi-permeable membranes that allow the movement of water across them and favor hydrolytic degradation [30]. However, Scotchbond Universal is a one-bottle simplified adhesive, and there was no decrease in $\mu$ TBS after 6 months of storage, which differentiates this adhesive system in regards to degradation. Although 6 months of storage is a short time of evaluation, water has been shown to pass through adhesives that do not contain a hydrophobic layer in the first minutes after application on dentin [31].

SEM was used to determine the failure mode. This observation allows analyzing whether the methodology used provides bond strength values that correspond to the adhesive-dentin interface, which is the desired bond strength. Secondly, regions that are more susceptible to failure can be identified using SEM [32]. In the current study, mixed failures was the most common mode of failure for Scotchbond Universal and Clearfil SE Bond, which maintained an adhesive or composite resin bond to dentin. Interfacial failures were the most common for Scotchbond Multi-Purpose. The failure analysis demonstrates that the adhesive systems used in the current study had a stronger bond to dentin because pure adhesive failures did not occur. In addition, a change in failure mode was not observed between specimens evaluated at $24 \mathrm{~h}$ and at 6 months of storage. This finding agrees with the $\mu$ TBS values, which did not exhibit statistically significant changes between the two periods of evaluation. The mixed failures were characterized in two different patterns: a) interfacial failures associated with cohesive failure in composite resin or b) cohesive failure in adhesive associated with cohesive failure in composite resin. Moreover, a similar distribution of these failures occurred for the adhesive systems.

\section{CONCLUSION}

The results of the current study demonstrate that the $\mu$ TBS for Scotchbond Universal is comparable to Clearfil SE Bond and Scothbond Multi-Purpose when adhering to dentin. Scotchbond Universal applied in the self-etch mode and Clearfil SE Bond revealed higher bond stability compared to the etch-and-rinse mode.

\section{CONFLICT OF INTEREST}

The authors confirm that this article content has no conflicts of interests.

\section{ACKNOWLEDGEMENTS}

The authors thank Professor Hélio Radke Bittencourt for the statistical analysis.

\section{REFERENCES}

[1] Van Meerbeek B, De Munck J, Yoshida Y, et al. Buonocore memorial lecture. Adhesion to enamel and dentin: current status and future challenges. Oper Dent 2003; 28(3): 215-35. [PMID: 12760693]

[2] Perdigão J, Heymann HO. Bonding to enamel and dentin: a brief history and state of the art. Quintessence Int 1995; 26: 95-110. [PMID: 7568728]

[3] Cardoso MV, de Almeida Neves A, Mine A, et al. Current aspects on bonding effectiveness and stability in adhesive dentistry. Aust Dent J 2011; 56(Suppl 1): 31-44. [http://dx.doi.org/10.1111/j.1834-7819.2011.01294.x] [PMID: 21564114]

[4] Pashley DH, Tay FR, Breschi L, et al. State of the art etch-and-rinse adhesives. Dent Mater 2011; 27(1): 1-16. 
[http://dx.doi.org/10.1016/j.dental.2010.10.016] [PMID: 21112620]

[5] Nakabayashi N, Kojima K, Masuhara E. The promotion of adhesion by the infiltration of monomers into tooth substrates. J Biomed Mater Res $1982 ; 16(3): 265-73$.

[http://dx.doi.org/10.1002/jbm.820160307] [PMID: 7085687]

[6] Miyazaki M, Onose H, Iida N, Kazama H. Determination of residual double bonds in resin-dentin interface by Raman spectroscopy. Dent Mater 2003; 19(3): 245-51.

[http://dx.doi.org/10.1016/S0109-5641(02)00039-8] [PMID: 12628438]

[7] Breschi L, Mazzoni A, Ruggeri A, Cadenaro M, Di Lenarda R, De Stefano Dorigo E. Dental adhesion review: aging and stability of the bonded interface. Dent Mater 2008; 24(1): 90-101. [http://dx.doi.org/10.1016/j.dental.2007.02.009] [PMID: 17442386]

[8] Sarr M, Kane AW, Vreven J, et al. Microtensile bond strength and interfacial characterization of 11 contemporary adhesives bonded to burcut dentin. Oper Dent 2010; 35(1): 94-104.

[http://dx.doi.org/10.2341/09-076-L] [PMID: 20166416]

[9] Hashimoto M, Fujita S, Nagano F, Ohno H, Endo K. Ten-years degradation of resin-dentin bonds. Eur J Oral Sci 2010; 118(4): 404-10. [http://dx.doi.org/10.1111/j.1600-0722.2010.00744.x] [PMID: 20662915]

[10] Lo Giudice G, Cicciù M, Cervino G, Lizio A, Visco AM. Flowable resin and marginal gap on tooth third medial cavity involving enamel and radicular cementum: a SEM evaluation of two restoration techniques. Indian J Dent Res 2012; 23(6): 763-9. [http://dx.doi.org/10.4103/0970-9290.111256] [PMID: 23649060]

[11] Salvio LA, Hipólito VD, Martins AL, de Goes MF. Hybridization quality and bond strength of adhesive systems according to interaction with dentin. Eur J Dent 2013; 7(3): 315-26. [http://dx.doi.org/10.4103/1305-7456.115416] [PMID: 24926212]

[12] Anchieta RB, Machado LS, Martini AP, et al. Effect of long-term storage on nanomechanical and morphological properties of dentinadhesive interfaces. Dent Mater 2015; 31(2): 141-53.

[http://dx.doi.org/10.1016/j.dental.2014.11.010] [PMID: 25529501]

[13] Hegde MN, Hegde P, Chandra CR. Morphological evaluation of new total etching and self etching adhesive system interfaces with dentin. J Conserv Dent 2012; 15(2): 151-5.

[http://dx.doi.org/10.4103/0972-0707.94589] [PMID: 22557814]

[14] Yoshiyama M, Matsuo T, Ebisu S, Pashley D. Regional bond strengths of self-etching/self-priming adhesive systems. J Dent 1998; 26(7): 609-16. [http://dx.doi.org/10.1016/S0300-5712(97)00046-8] [PMID: 9754751]

[15] Tay FR, Gwinnett AJ, Pang KM, Wei SH. Resin permeation into acid-conditioned, moist, and dry dentin: a paradigm using water-free adhesive primers. J Dent Res 1996; 75(4): 1034-44.

[http://dx.doi.org/10.1177/00220345960750040601] [PMID: 8708133]

[16] Tay FR, Sano H, Carvalho R, Pashley EL, Pashley DH. An ultrastructural study of the influence of acidity of self-etching primers and smear layer thickness on bonding to intact dentin. J Adhes Dent 2000; 2(2): 83-98. [PMID: 11317404]

[17] Yoshida Y, Yoshihara K, Nagaoka N, et al. Self-assembled nano-layering at the adhesive interface. J Dent Res 2012; 91(4): $376-81$. [http://dx.doi.org/10.1177/0022034512437375] [PMID: 22302145]

[18] Miyazaki M, Sato M, Onose H, Moore BK. Influence of thermal cycling on dentin bond strength of two-step bonding systems. Am J Dent 1998; 11(3): 118-22. [PMID: 9823072]

[19] Wang Y, Spencer P. Quantifying adhesive penetration in adhesive/dentin interface using confocal Raman microspectroscopy. J Biomed Mater Res 2002; 59(1): 46-55. [http://dx.doi.org/10.1002/jbm.1215] [PMID: 11745536]

[20] Hashimoto M, Ohno H, Kaga M, Sano H, Endo K, Oguchi H. The extent to which resin can infiltrate dentin by acetone-based adhesives. J Dent Res 2002; 81(1): 74-8. [http://dx.doi.org/10.1177/154405910208100116] [PMID: 11820372]

[21] Marchesi G, Frassetto A, Mazzoni A, et al. Adhesive performance of a multi-mode adhesive system: 1-year in vitro study. J Dent 2014; 42(5): 603-12. [http://dx.doi.org/10.1016/j.jdent.2013.12.008] [PMID: 24373855]

[22] Yoshida Y, Nagakane K, Fukuda R, et al. Comparative study on adhesive performance of functional monomers. J Dent Res 2004; 83(6): 454-8. [http://dx.doi.org/10.1177/154405910408300604] [PMID: 15153451]

[23] Oliveira SS, Pugach MK, Hilton JF, Watanabe LG, Marshall SJ, Marshall GW Jr. The influence of the dentin smear layer on adhesion: a selfetching primer vs. a total-etch system. Dent Mater 2003; 19(8): 758-67. [http://dx.doi.org/10.1016/S0109-5641(03)00023-X] [PMID: 14511734]

[24] Peumans M, De Munck J, Van Landuyt KL, Poitevin A, Lambrechts P, Van Meerbeek B. Eight-year clinical evaluation of a 2-step self-etch 
adhesive with and without selective enamel etching. Dent Mater 2010; 26(12): 1176-84.

[http://dx.doi.org/10.1016/j.dental.2010.08.190] [PMID: 20947155]

[25] Fukegawa D, Hayakawa S, Yoshida Y, Suzuki K, Osaka A, Van Meerbeek B. Chemical interaction of phosphoric acid ester with hydroxyapatite. J Dent Res 2006; 85(10): 941-4. [http://dx.doi.org/10.1177/154405910608501014] [PMID: 16998137]

[26] Mitra SB, Lee CY, Bui HT, Tantbirojn D, Rusin RP. Long-term adhesion and mechanism of bonding of a paste-liquid resin-modified glassionomer. Dent Mater 2009; 25(4): 459-66.

[http://dx.doi.org/10.1016/j.dental.2008.09.008] [PMID: 19041127]

[27] Lin A, McIntyre NS, Davidson RD. Studies on the adhesion of glass-ionomer cements to dentin. J Dent Res 1992; 71(11): $1836-41$. [http://dx.doi.org/10.1177/00220345920710111401] [PMID: 1401448]

[28] Tay FR, Pashley DH. Aggressiveness of contemporary self-etching systems. I: Depth of penetration beyond dentin smear layers. Dent Mater 2001; 17(4): 296-308

[http://dx.doi.org/10.1016/S0109-5641(00)00087-7] [PMID: 11356206]

[29] Cadenaro M, Antoniolli F, Sauro S, et al. Degree of conversion and permeability of dental adhesives. Eur J Oral Sci 2005; $113(6)$ : 525-30. [http://dx.doi.org/10.1111/j.1600-0722.2005.00251.x] [PMID: 16324144]

[30] Tay FR, Pashley DH, Suh BI, Carvalho RM, Itthagarun A. Single-step adhesives are permeable membranes. J Dent 2002; 30(7-8): 371-82. [http://dx.doi.org/10.1016/S0300-5712(02)00064-7] [PMID: 12554121]

[31] Chersoni S, Suppa P, Grandini S, et al. In vivo and in vitro permeability of one-step self-etch adhesives. J Dent Res 2004; 83(6): 459-64. [http://dx.doi.org/10.1177/154405910408300605] [PMID: 15153452]

[32] Armstrong SR, Boyer DB, Keller JC. Microtensile bond strength testing and failure analysis of two dentin adhesives. Dent Mater 1998; 14(1): 44-50.

[http://dx.doi.org/10.1016/S0109-5641(98)00008-6] [PMID: 9972150]

(C) Manfroi et al.; Licensee Bentham Open.

This is an open access article licensed under the terms of the Creative Commons Attribution-Non-Commercial 4.0 International Public License (CC BY-NC 4.0) (https://creativecommons.org/licenses/by-nc/4.0/legalcode), which permits unrestricted, non-commercial use, distribution and reproduction in any medium, provided the work is properly cited. 